Thorax (1968), 23, 356.

\title{
Mucoid impaction of the bronchi in relation to asthma and plastic bronchitis
}

\author{
A. D. MORGA A N D W BOGOMOLETZ \\ From the Morbid Anatomy Department, Westminster Medical School, London
}

\begin{abstract}
Mucoid impaction of the bronchi is a condition which deserves wider recognition in this country. It should be considered in any asthmatic subject who may be suspected on clinical or radiological grounds to be suffering from pulmonary tuberculosis or neoplasm. Although 120 cases have been reported since 1951, there are no reports from this country in the British literature. As we have seen three cases in one hospital, we believe that mucoid impaction is being diagnosed under other headings, for example plastic bronchitis. Most of the changes in lungs removed for mucoid impaction are those of asthma, although other factors may play a part. We have compared the pathologies of mucoid impaction, asthma, and plastic bronchitis, and conclude that, while they overlap considerably, they are not identical. Mucoid impaction is an uncommon complication of asthma and certain forms of bronchitis; plastic bronchitis has a much wider aetiological background and is not a pathological entity.
\end{abstract}

The term 'mucoid impaction of the bronchus' was coined by Shaw (1951) to denote retention of an inspissated mucous cast in a bronchus, causing localized bronchiectasis and pneumonitis. The clinical features were those of mild cough, often non-productive, occasional haemoptyses, and sometimes chest pain or dyspnoea. In some cases there was a history of febrile attacks, responding to treatment but tending to recur, and sometimes subsiding after the expectoration of large plugs of firm, tenacious mucus. Most were diagnosed clinically and radiologically as tuberculosis or neoplasm ; a few were quite asymptomatic and picked up only on chest radiographs. At operation a hard plug of inspissated secretion was found distending a second or third order bronchus. In four-fifths of the cases impaction occurred in an upper lobe; occasionally more than one lobe was affected. Eight of Shaw's original 10 cases were asthmatics, the other two being diagnosed as chronic obstructive bronchitis.

Although Shaw was unable to find similar accounts in the literature of the preceding 14 years, 128 cases have now been described, which would suggest that this is either a new syndrome or that it has masqueraded in the past under other names. The only article on the subject in the British literature originated in Australia (Wilson, 1964), and it has been suggested that the humidity of our climate may account for our apparent im- munity (Hutcheson, Shaw, Paulson, and Kee, $\stackrel{\mathbb{D}}{\circ}$ 1960). As we have seen three cases in our own $\overrightarrow{\vec{B}}$ hospital, we suspect that British cases have gone 3 either unrecognized or unrecorded. We also sus-? pect that the old-fashioned diagnosis of plastic (oro fibrinous) bronchitis may have concealed a few mucoid impactions in the past.

Before proceeding to deal with the overlapping pathologies of mucoid impaction, plastic bronchi-o tis, and bronchial asthma, we present the follow ing cases as an introduction to the clinical picture.

\section{CASE REPORTS}

CASE 1 A Maltese merchant aged 55 at the time of lobectomy was a heavy smoker, and for the previous three to four years he had complained of a wheezen in the chest, made worse by coming into contact with. the straw he imported from Morocco. He had a cough, $N$ worse in the mornings, producing a small amount of N white tenacious sputum, but had no haemoptyses. $\mathrm{He}^{\mathrm{\omega}}$ was referred for investigation of breathlessness and a tired feeling. On physical examination the chesto seemed to be clear, but the radiograph revealed an opacity in the left upper lobe, probably involving two? segments. W.B.C. $10,200 /$ c.mm. (918 eosinophils). The sputum was muco-purulent with $1 \%$ eosinophils buto no Charcot-Leyden crystals or significant organisms.

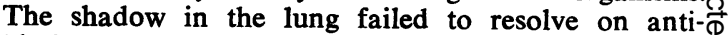
biotic therapy, and on suspicion of carcinoma thoracotomy was undertaken. A mass was felt in the left upper lobe, which was resected. He was discharged a? month later. 


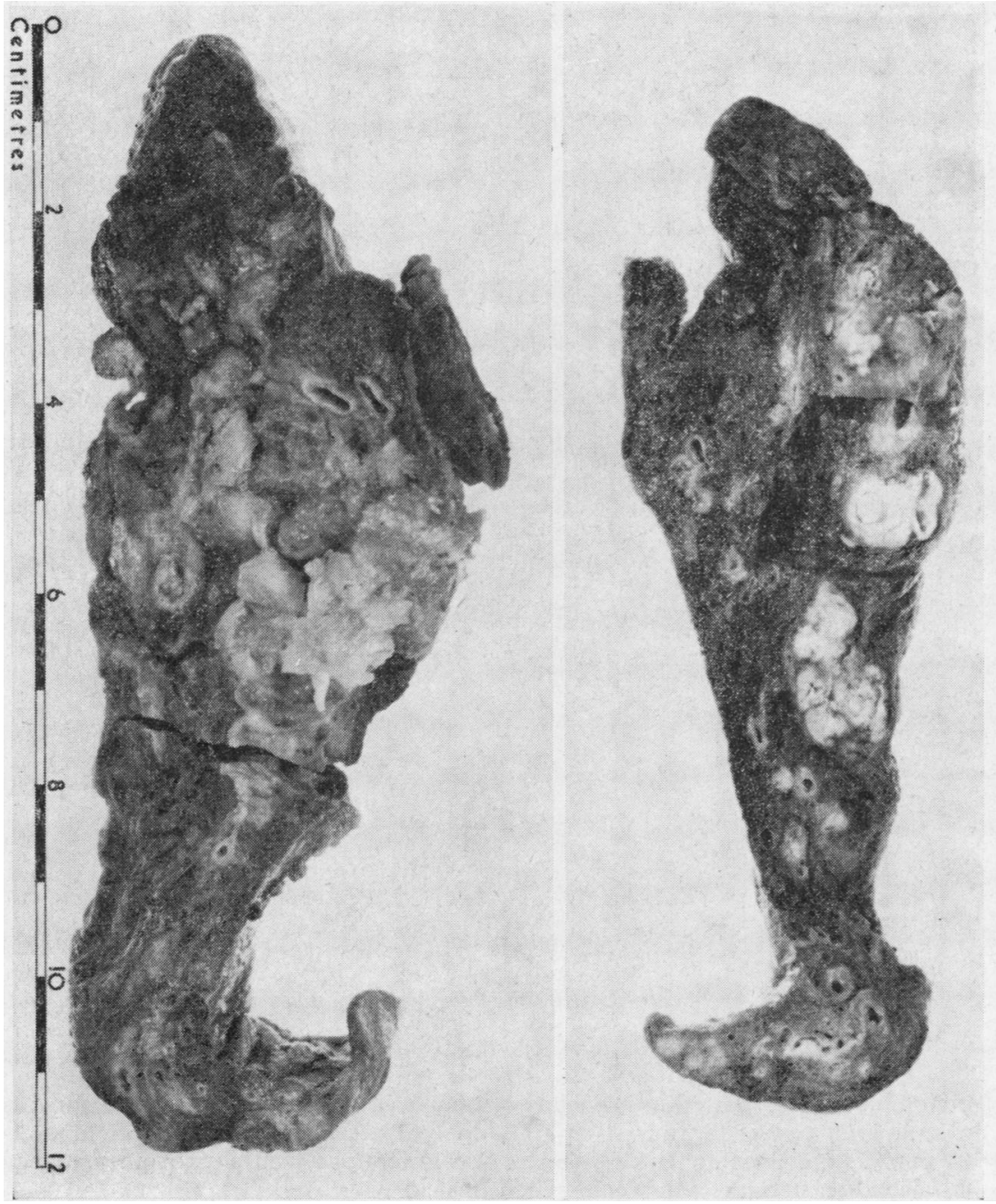

FIG. 1. Case 1. Mucoid cast obstructing bronchus (left) and causing bronchiectatic abscesses (right).

Pathology The posterior segmental bronchus was grossly distended $(1.5 \mathrm{~cm}$. in diameter) by a white, glistening cast of rubbery consistence. Beyond the obstruction the lung was riddled with creamy white lesions, mostly about $1 \mathrm{~cm}$. in diameter, with pultaceous contents (Fig. 1). When the cast was dislodged, the bronchial lumen was seen to be sacculated by a series of transverse crescentic folds in the mucosa, deeply indenting the cast and probably constituting a factor in its impaction (Fig. 2).

CASE 2 A dental surgeon aged 37 at the time of lobectomy had been 'chesty' all his life with asthmalike episodes and hay-fever, and he was a heavy smoker. Previous illnesses had been erythema nodosum in his teens and virus pneumonia three years before his operation.

The present illness began with an attack of 'viral' chest infection in the form of a cough with purulent sputum. The chest radiograph revealed a diffuse opacity in the left upper lobe. This cleared but recurred two months later, and he was admitted for investigation, although he felt well and had no dyspnoea. Apart from expiratory wheezes over the right upper lobe there were no physical signs. He was bringing up sputum, however, which was tinged with blood but contained no significant organisms. W.B.C. 12,500/c.mm. (750 eosinophils). Further radiographs, including tomograms, were suggestive of bronchial carcinoma, and thoracotomy was advised. At operation an irregularly shaped mass of leathery consistence was discovered in the left apico-posterior segmental bronchus, and the lobe was resected. 


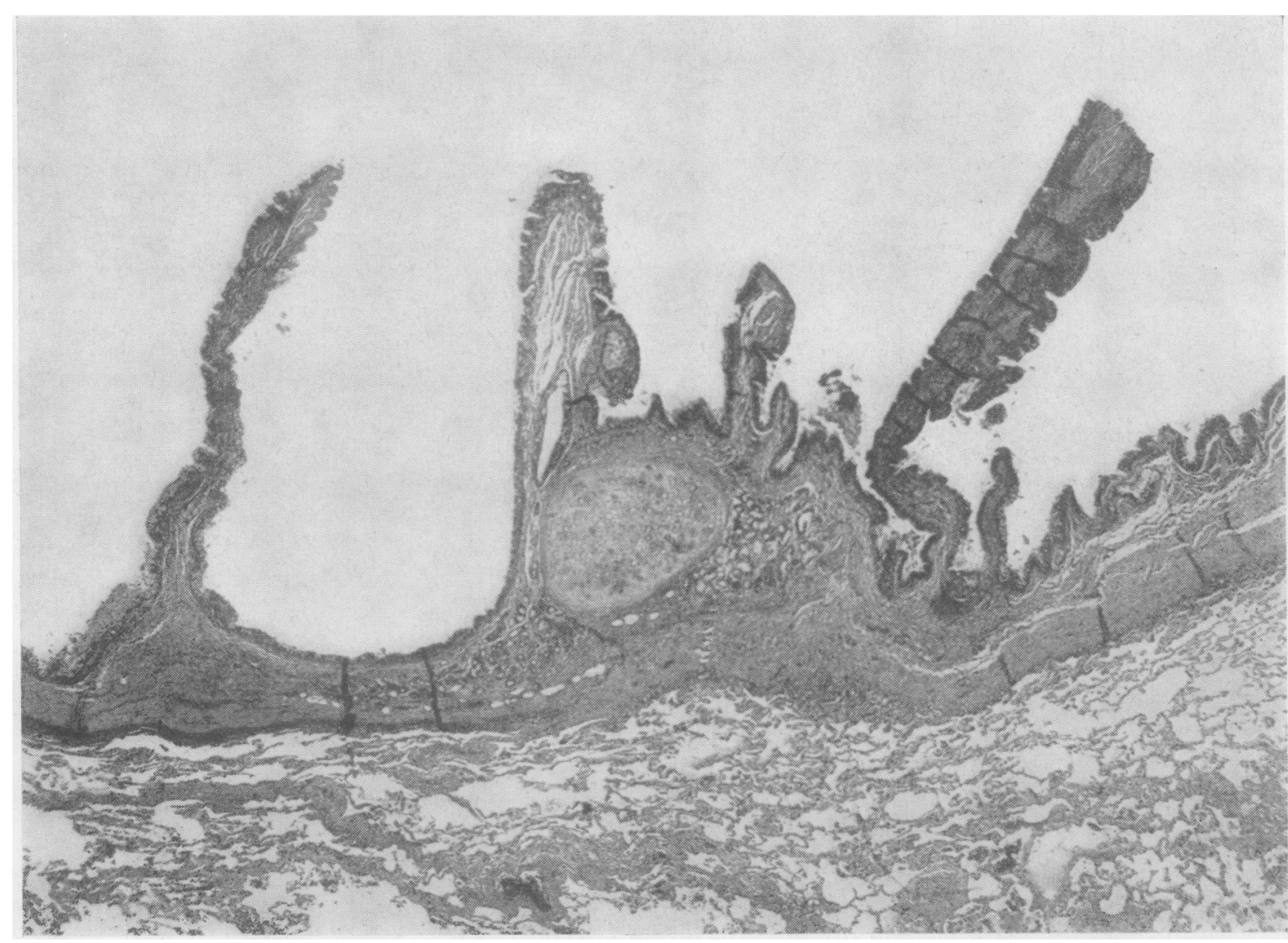

FIG. 2. Case 1. Longitudinal section of obstructed bronchus showing mucosal folds. Haematoxylin-eosin. $\times 21$.

Pathology On section, the apico-posterior bronchus was distended by a tapering cone of firm material, $5 \mathrm{~cm}$. long and $14 \mathrm{~mm}$. in diameter at its base (Fig. 3). This was a bronchial cast with a tan-coloured cortex, $1 \mathrm{~mm}$. thick, and a cream-coloured core, and in places it was firmly adherent to the bronchial lining. The surrounding lung showed slight emphysema only.

CASE 3 A married woman canteen assistant aged 44 at the time of pneumonectomy gave a history of chest troubles since childhood and 'asthmatic attacks for many years, associated with bronchitis', especially during the winter months. She was a heavy smoker, and she occasionally had acute asthmatic attacks which responded to adrenaline injections. Seven years before her operation she had had pleurisy.

She was admitted to hospital for investigation of dyspepsia and loss of weight, and on a routine chest radiograph (the first she had ever had) a dense opacity was seen in the posterior segment of the right upper lobe, bulging into the fissure (Fig. 4). Further questioning elicited that she had been getting breathless during the last year. Her cough was occasionally productive, but there was no history of haemoptyses. Bronchial carcinoma or tuberculosis was suspected, and thoraco- tomy was undertaken. At operation one hard lesion was palpated in the right upper lobe and a second in the lower lobe, and a right pneumonectomy was per-o formed.

For the next year she had recurrent pyrexia, cough, $\rightarrow 0$ and purulent sputum, responding to antibiotics but三. relapsing when they were discontinued. During one of $N$ these the W.B.C. count was $10,000 / \mathrm{cmm}$. $\left(1,800^{\circ}\right.$ eosinophils). Eight years later she was again admitted with bronchial spasm, and the W.B.C. count was 6,500/c.mm., 975 eosinophils). When last seen someo months later the left lung fields were clear.

Pathology In the posterior segment of the righte upper lobe were three hard round lesions, the largest $2 \mathrm{~cm}$. in diameter. These were situated below the pleura just above the level of the horizontal fissure, and were due to cystic distension of the right uppero posterior segmental bronchus and its branches, which were filled by brown material with a toffee-like con- $\sigma$ sistence (Fig. 5). It was not possible to discover their point of communication with the rest of the bronchiab tree.

The anterior segment of the lower lobe wast destroyed by a confluence of bronchiectatic abscesses? 


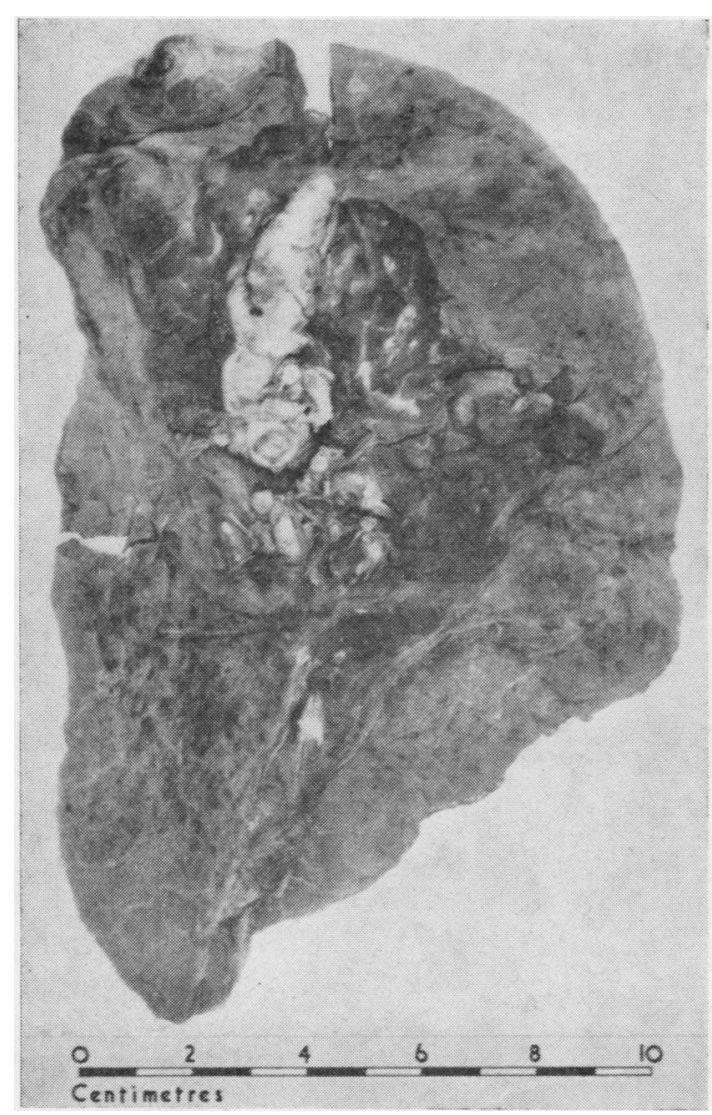

FIG. 3. Case 2. Obstruction of left apico-posterior bronchus by mucoid cast.

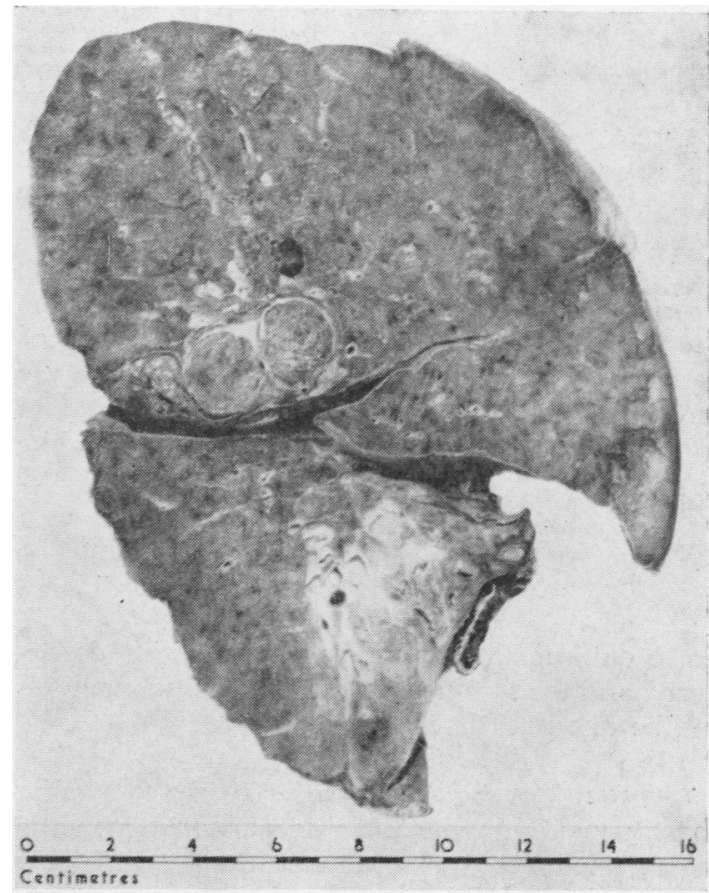

FIG. 5. Case 3. Right lung showing cystic distension of upper lobe bronchi by casts; pneumonitis and bronchiectatic abscesses of lower lobe.
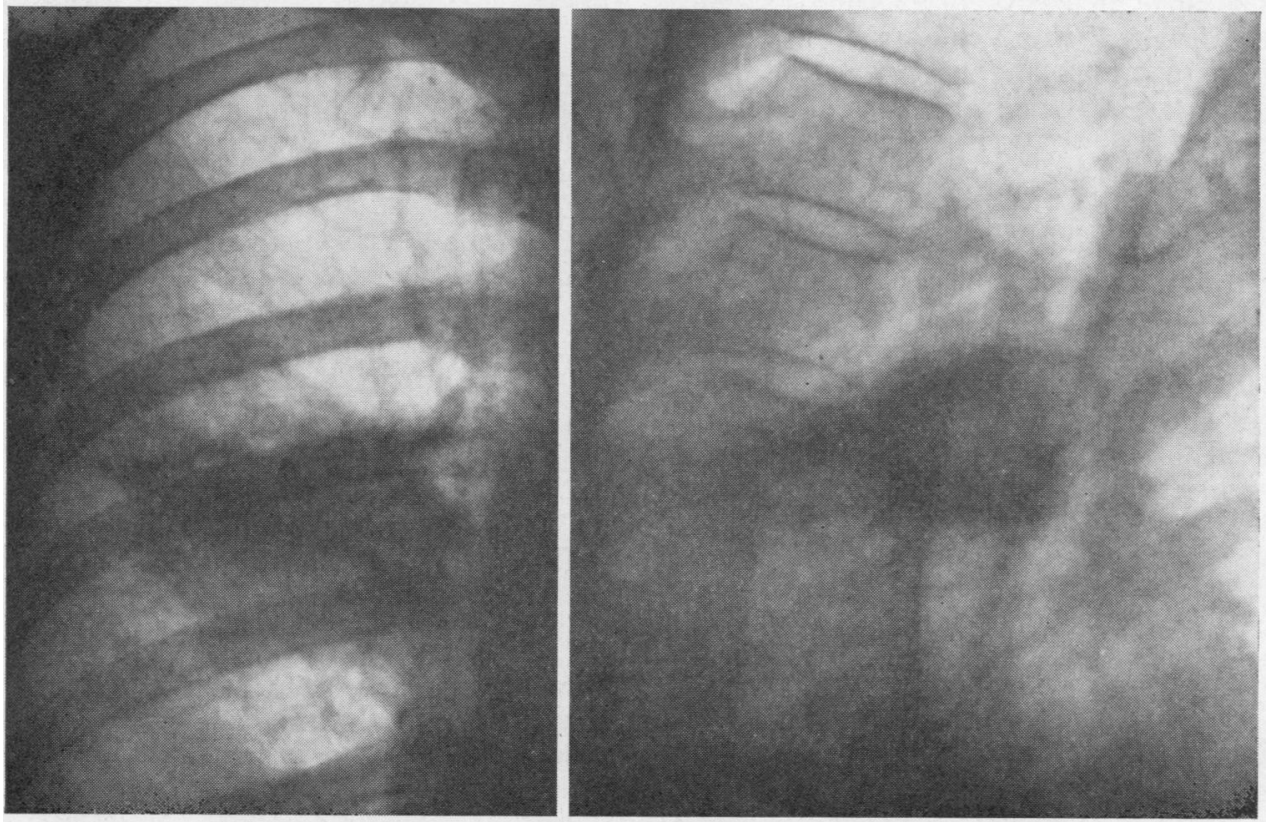

FIG. 4. Case 3. Chest radiograph showing opacity of right mid-zone: A.P. (left) and lateral (right). 
producing a yellow wedge-shaped lesion, $4 \mathrm{~cm}$. broad. The segmental bronchus appeared to be narrowed and blocked by brown material similar to that in the upper lobe.

COMMENT Despite the variability of the presenting symptoms, there is a background of asthmalike attacks, lesser allergies, and blood eosinophilia in all three cases. The presence of bronchiectatic abscesses in two of them is in contrast to the paucity of physical signs. We have arranged the cases in what we believe to be the order of diuturnity of the bronchial casts, which are described respectively as rubbery, leathery, and toffee-like in consistence, and ranged from white to dark brown in colour.

\section{MICROSCOPIC CHANGES}

To avoid repetition these are dealt with collectively, and the significance of the staining reactions will be discussed later.

BRONCHIAL CASTS All three casts have similar constituents, although their proportions vary, and the appearances are at once unusual and highly characteristic. Haematoxylin-eosin preparations reveal broad layers, laminated or irregularly whorled, of a lightly basophilic, relatively acellular substance which stains like mucus (as shown by Alcian blue and P.A.S.) interdigitating with an acidophilic and highly cellular material which stains like fibrin (red with Lendrum's M.S.B., deep purple with P.T.A.H.) and negatively for mucin (Fig. 6). The two materials are sharply separated, and a study of the variations in their relative proportions suggests that the mucoid component diminishes with the age and degree of inspissation of the cast. Thus, in case 1 , where the cast was white and moist, three-quarters of the section stains for mucin, whereas in case 3 , where the secretion was brown and toffee-like,. only onequarter was mucin-positive. In case 2 the proportions are roughly equal, which agrees with our macroscopic impression of the age of the cast. These observations hold true for the proximal, more inspissated end of the cast: distally, it becomes more demonstrably mucoid, as might be expected. The cells in the acidophilic zones have a cramped appearance, their nuclei stain weakly with haematoxylin, and their cell envelopes are not distinguishable (Fig. 7). Mononucleated and polymorphonuclear forms are seen, but one cannot identify desquamated mucosal cells with certainty. Small clusters of eosinophils are present in the mucoid areas, and along the line of junction with

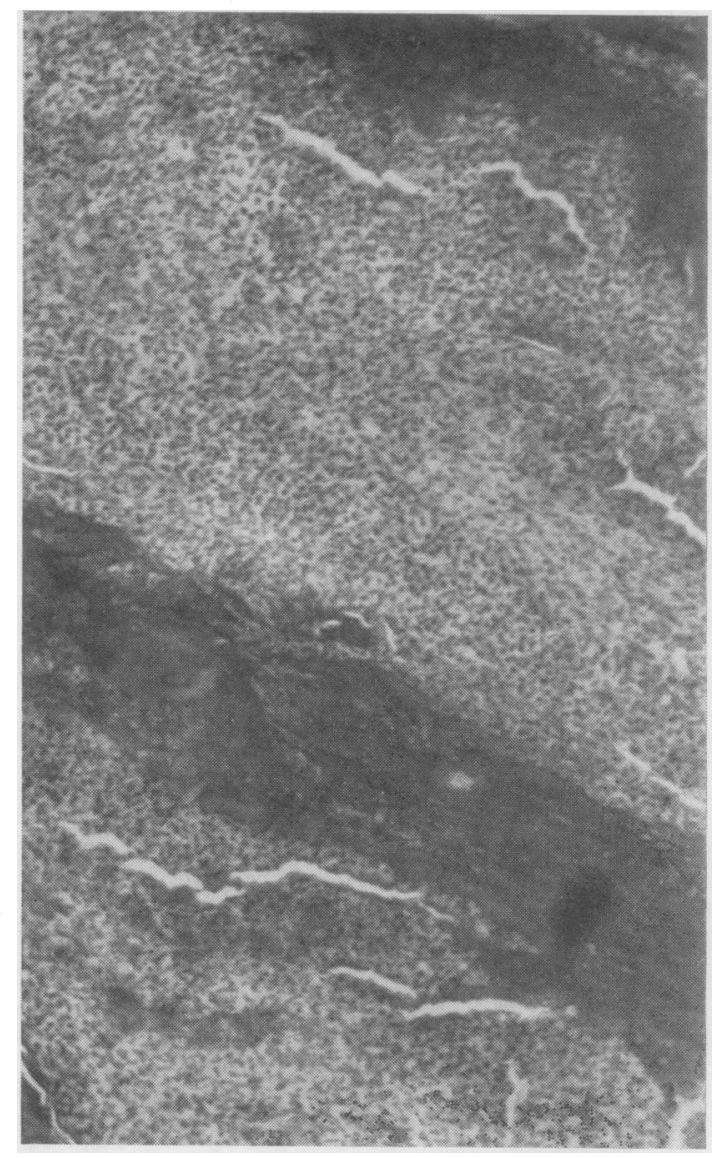

FIG. 6. Case 2. Photomicrograph of cast. The darkerstaining bands stain like mucus, the lighter cellular areas like fibrin. Haematoxylin-eosin. $\quad \times 135$.

the acidophil zones are numerous CharcotLeyden crystals-needle-shaped octahedra which $N$ have recently been shown to be formed from the granules of degenerating eosinophils (Welsh, 1959). These crystals stain purple with P.T.A.H. $\omega$ and red with M.S.B. (Fig. 8). Similar crystals are? sometimes prominent round foci of anuclear ando strongly acidophilic granular detritus. Gram's stain reveals occasional cocci round the periphery? of the cast (and incidentally does not demonstrate $\frac{T}{T}$ any fibrin). None of the casts or tissues examined contained fungi.

BRONCHI Those surrounding the casts show the. features of chronic bronchitis- desquamation the superficial epithelium, cubical or squamoid meta-응 plasia, thickening of the basement membrane, and congestion and round-celled infiltration of the $\frac{\bar{\alpha}}{\partial}$ 


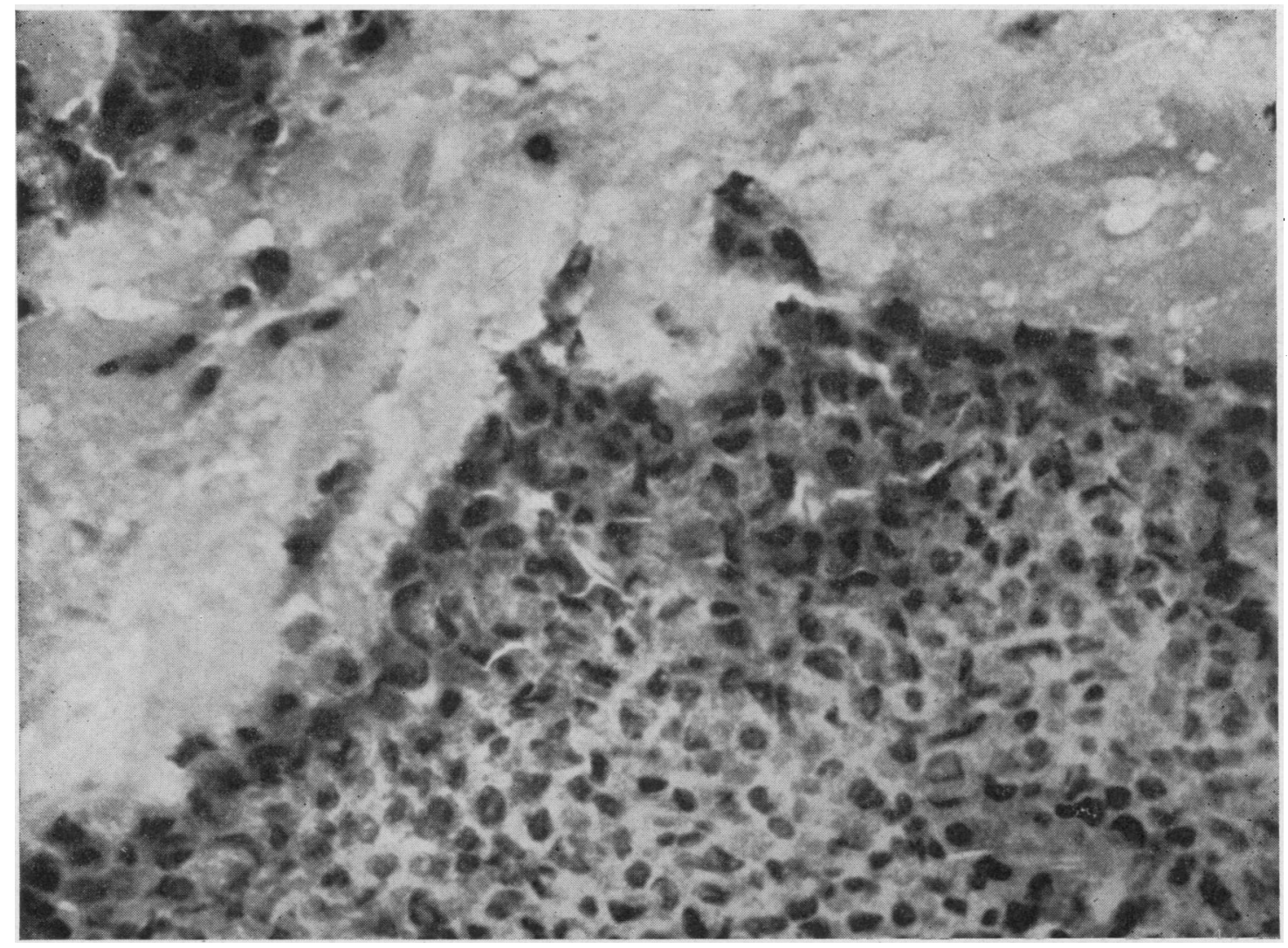

FIG. 7. Case 2. The homogeneous mucoid areas are sharply divided from the cellular zones. Haematoxylin-eosin. $\times 640$.

submucosa ; also some of the features of asthmagoblet-cell hyperplasia (Fig. 9), tissue eosinophilia, and hypertrophy of smooth muscle and mucous glands. In many places repeated desquamation has led to replacement by a flattened epithelium (Fig. 10) or even total denudation, so that the cast is directly adherent to the basement membrane, where it shows early signs of organization.

In case 1 the mucous glands are unusually large, and their ducts are distended (Fig. 11), whereas in case 3 they appear as small retention cysts, lying outside the ring of smooth muscle (Fig. 12). Where saccular bronchiectasis is extreme there is complete atrophy of bronchial muscle and cartilage.

Mucus retention, chronic inflammation, and tissue eosinophilia are continued down to the smaller bronchi. The bronchiectatic abscesses in case 1 have a caseous appearance, apparently due to the sterilizing effects of antibiotics. In cases 1 and 3 , in addition to pus and granular detritus, there are ragged clumps of intensely haematoxy- philic material, not fungal and probably condensed nuclear substance (Fig. 9). Sections from the macroscopically healthy parts of both lobes in case 3 show medium-sized bronchi with extreme goblet-cell metaplasia of their mucosa, with or without muco-cellular secretion into the lumen. Some adjoining bronchi, however, are practically normal.

LUNG PARENCHYMA In case 2 the only change is emphysematous distention of the subpleural alveoli. Cases 1 and 3 show the type of pneumonitis characteristic of advanced bronchiectasis, the picture being complicated in the former case by the presence of mucoid material and lipophages in groups of distended alveoli. None of the three showed atelectasis.

\section{ANALYSIS OF RECORDED CASES OF MUCOID IMPACTION}

Since Shaw's original paper 128 cases have been recorded. By far the largest series is that of the 


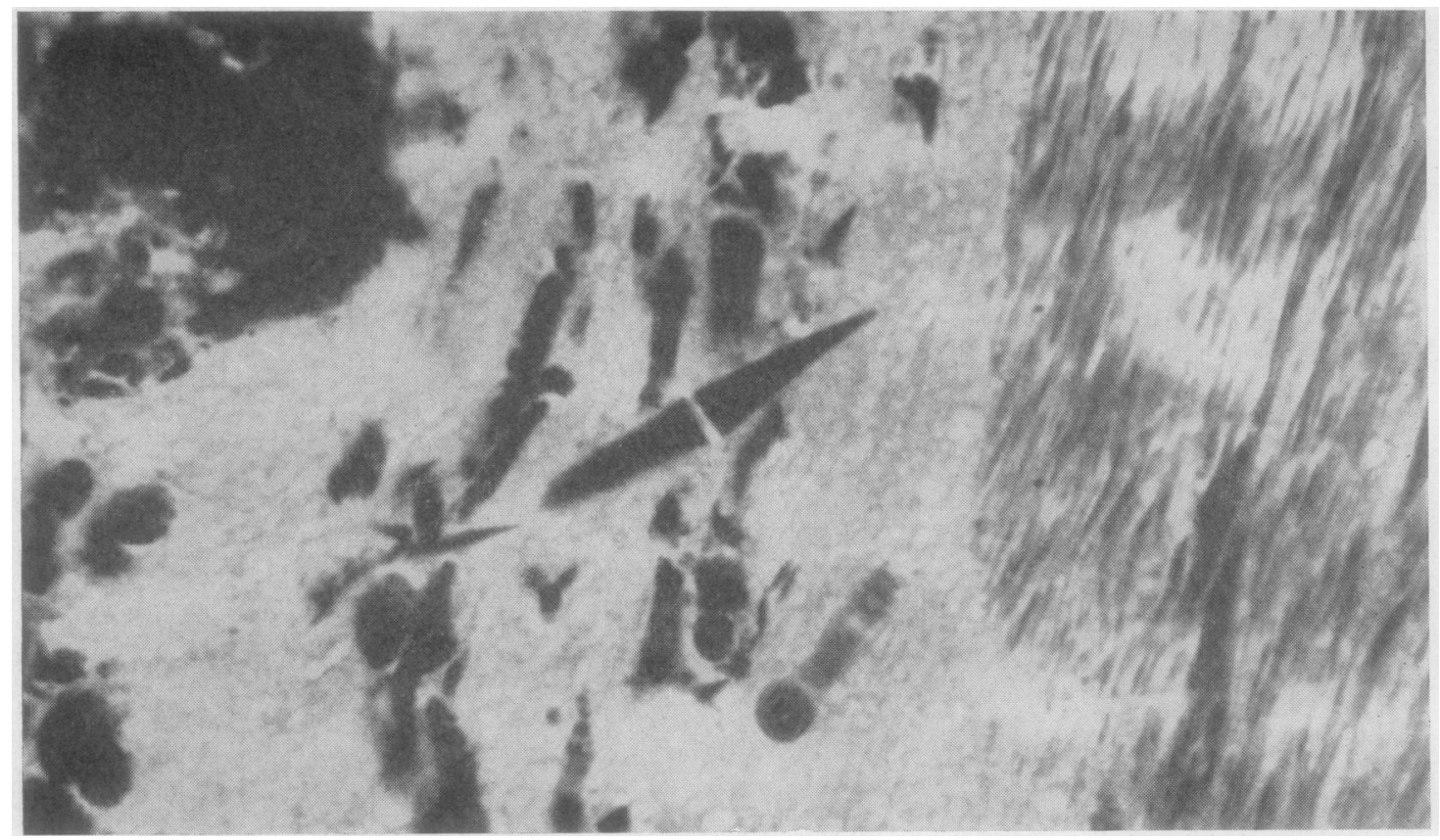

FIG. 8. Case 2. Charcot-Leyden crystals along boundary of mucoid and cellular zones. P.T.A.H. $\times 700$.

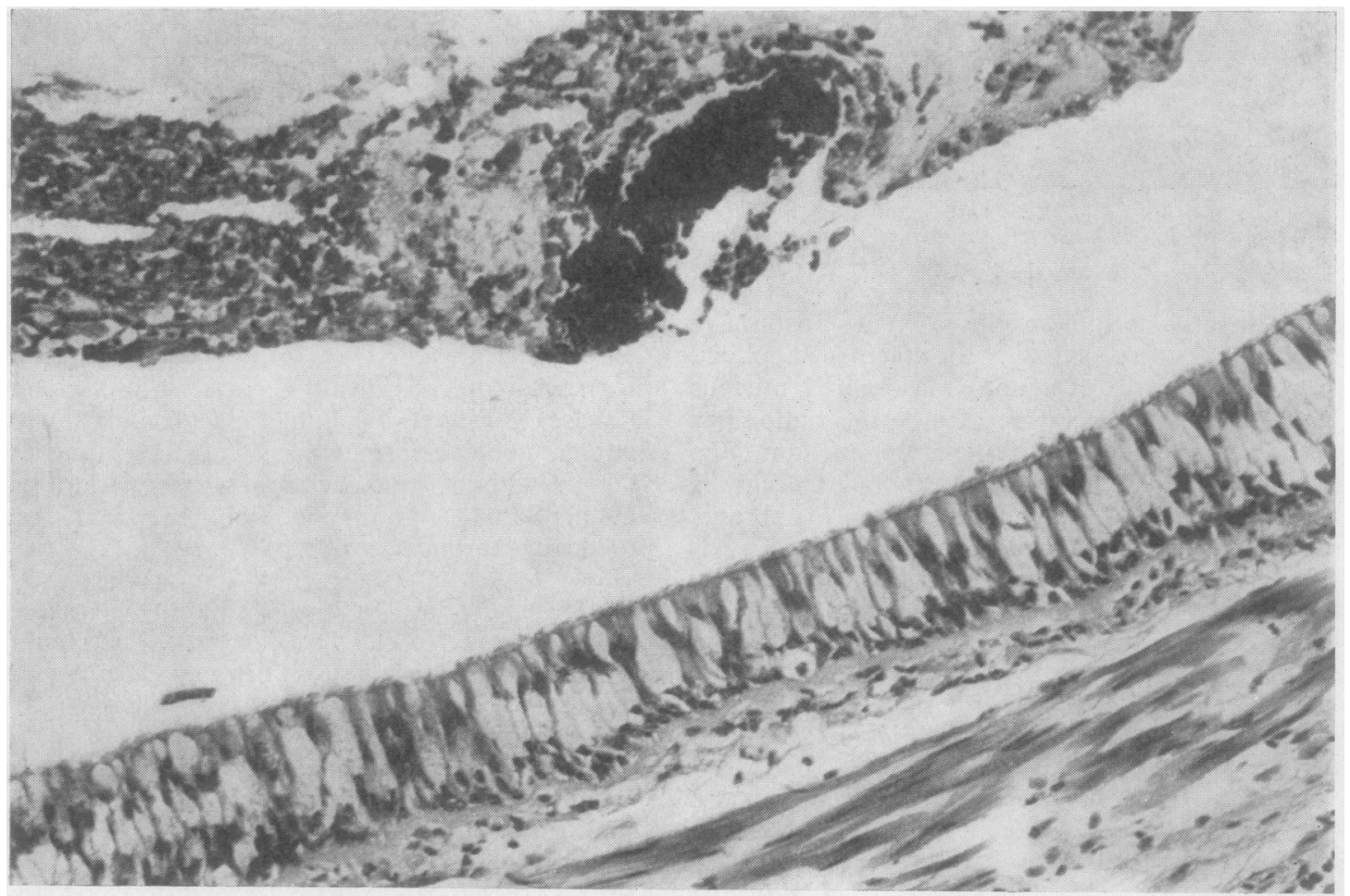

FIG. 9. Case 3. Goblet-cell hyperplasia of bronchial mucosa. The intensely haematoxyphile clump in the mucocellular exudate is nuclear detritus. Haematoxylin-eosin. $\times 160$. 


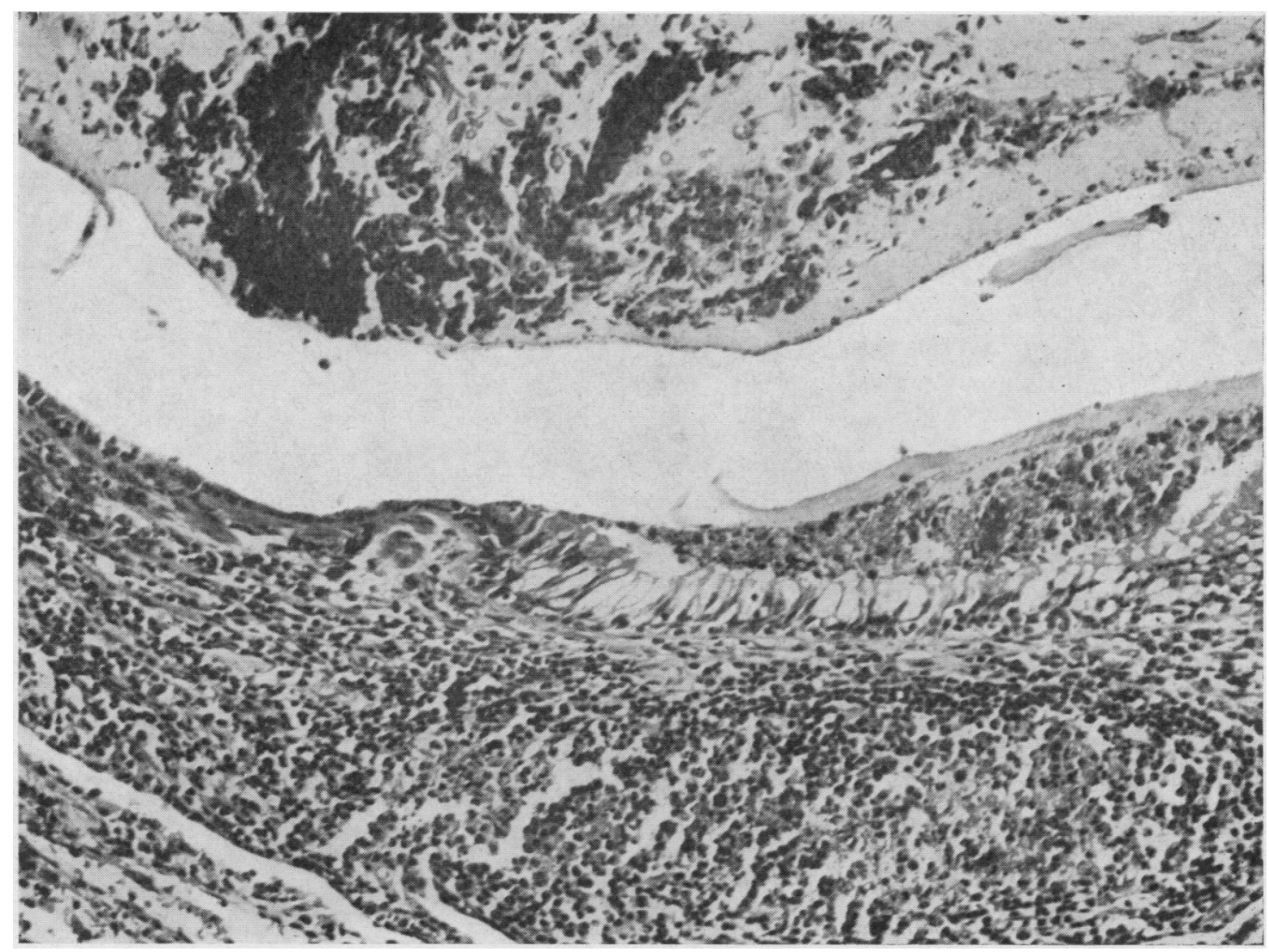

FIG. 10. Case 3. The goblet-cell hyperplasia of the bronchial mucosa (right) is abruptly replaced by a desquamated lining (left). Haematoxylin-eosin. $\times 170$.

Department of Thoracic Surgery, University of Texas (Urschel, Paulson, and Shaw, 1966), with an analysis of 85 cases, including those of Shaw (1951), Shaw, Paulson, and Kee (1957), and, as far as we can gather, Hutcheson et al. (1960). In this series there are no individual histories apart from Shaw's original 10 cases.

We have analysed 34 other case records (Gerrits, 1965 ; Greer, 1957 ; Harvey, Blacket, and Read, 1957 ; Hekking and Goemans, 1957 ; Keeley and Snead, 1965 ; Mannes and Severin, 1958; Sanerkin, Seal, and Leopold, 1966 ; Sheehan and Schonfeld, 1963 ; Smith and Clark, 1964 ; Tsai and Jenne, 1966; Wilson, 1964, and our own three cases), omitting a further nine because of lack of data (Carlson, Martin, Keegan, and Dailey, 1966 ; Greer, 1957, cases 6 to 8). We have also excluded the 23 children and adolescents suffering from mucoviscidosis, described by Waring, Brunt, and Hilman (1967). As the latter have a different agegroup and aetiology they are not strictly compar- able to the asthma-bronchitis cases. Our analysis is compared with the series of Urschel et al. (1966) in Tables I to III.

No case of single lower lobe impaction appeared in the series we have analysed, although the lower lobe was involved along with an upper or middle lobe in 13 of the 14 multiple impactions and in one case of bilateral lower lobe involvement (Smith and Clark, 1964, case 3).

Fifteen of the 34 cases were treated surgically, as compared with 40 of the Texas group's series of 85 .

RADIOLOGICAL APPEARANCES These are not considered here, as they have been amply described by others (Shaw et al., 1957 ; Harvey et al., 1957 ; Wilson, 1964 ; Urschel et al., 1966).

DIFFERENTIAL DIAGNOSIS The commoner misdiagnoses are pulmonary neoplasm, tuberculosis, bronchiectasis, or lung abscess. Transient eosino- 


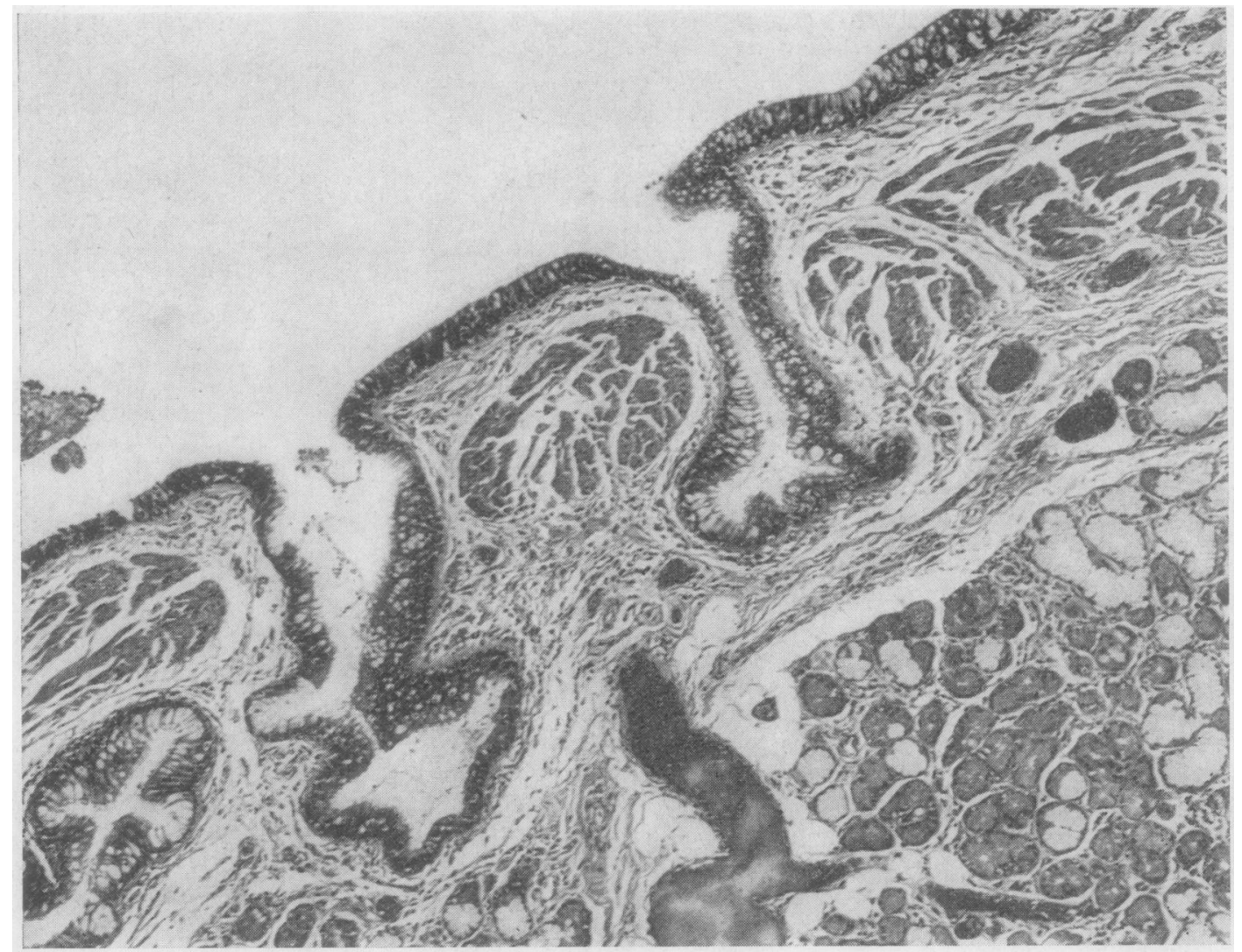

FIG. 11. Case 1. Distended ducts of bronchial mucosal glands showing goblet-cell hyperplasia. Haematoxylin-eosin. $\times 65$

T A B L E I

AGE AND SEX

\begin{tabular}{c|c|c}
\hline Years & $\begin{array}{c}\text { Present Analysis } \\
(34)\end{array}$ & $\begin{array}{c}\text { Urschel et al. (1966) } \\
(\mathbf{8 5})\end{array}$ \\
\hline $0-9$ & 0 & $4(4 \cdot 7 \%)$ \\
$10-19$ & $2(6 \%)$ & $8(9.4 \%)$ \\
$20-29$ & $7(20 \cdot 6 \%)$ & $14(16 \cdot 5 \%)$ \\
$30-39$ & $4(12 \%)$ & $16(18.8 \%)$ \\
$40-49$ & $8(24 \%)$ & $18(21.2 \%)$ \\
$50-59$ & $9(26 \cdot 5 \%)$ & $12(14 \cdot 1 \%)$ \\
$60+$ & $4(12 \%)$ & $13(15 \cdot 3 \%)$ \\
\hline Sex incidence & $\mathrm{M}: \mathrm{F}=16: 18$ & $\mathrm{M}: \mathrm{F}=45: 40$ \\
\hline
\end{tabular}

philia accompanying febrile attacks may lead to the diagnosis of Loeffler's syndrome (Harvey et al., 1957). Pulmonary aspergillosis may also produce asthmatic symptoms (Hinson, Moon, and Plummer, 1952) or simulate mucoid impaction (Tsai and Jenne, 1966; Sanerkin, Seal, and Leopold, 1966). Smith and Clark (1964) record a case of true mucoid impaction in which skin tests were positive to aspergillus antigen.
T A B L E I I

CLINICAL FEATURES

\begin{tabular}{|c|c|c|}
\hline & $\begin{array}{c}\text { Present Analysis } \\
\text { (34) }\end{array}$ & $\begin{array}{c}\text { Urschel } e t \text { al. } \\
\text { (1966) (85) }\end{array}$ \\
\hline $\begin{array}{ll}\text { Asthma, bronchitis } & \ldots \\
\text { Productive cough } & \ldots \\
\text { Chest pain }\end{array}$ & $\begin{array}{l}25(73.5 \%) \\
26(76.5 \%) \\
8(23.5 \%)\end{array}$ & $\begin{array}{l}71(83.8 \%) \\
53(62.4 \%) \\
28(33 \%)\end{array}$ \\
\hline 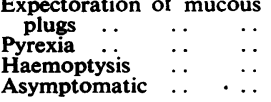 & $\begin{array}{l}15(44 \%) \\
12(35 \cdot 3 \%) \\
9(26 \cdot 5 \%) \\
2(6 \%)\end{array}$ & $\begin{array}{c}25(29.4 \%) \\
31(36.5 \%) \\
22(25.9 \%) \\
5(5.9 \%)\end{array}$ \\
\hline
\end{tabular}

T A B L E I I I

LOCATION OF LESION

\begin{tabular}{ll|c|c}
\hline \multicolumn{1}{c|}{ Site } & & $\begin{array}{c}\text { Present Series } \\
(34)\end{array}$ & $\begin{array}{c}\text { Urschel } \text { et al. } \\
(\mathbf{1 9 6 6 )}(\mathbf{8 5 )})\end{array}$ \\
\hline $\begin{array}{llc}\text { Upper lobe alone } \\
\text { Middle lobe alone }\end{array}$ & $\cdots$ & 17 & 42 \\
Lower lobe alone & $\cdots$ & 0 & 6 \\
$\begin{array}{l}\text { More than one lobe } \\
\text { involved }\end{array}$ & 0 & 18 \\
Not definitely stated & $\cdots$ & 14 & 19 \\
\hline
\end{tabular}




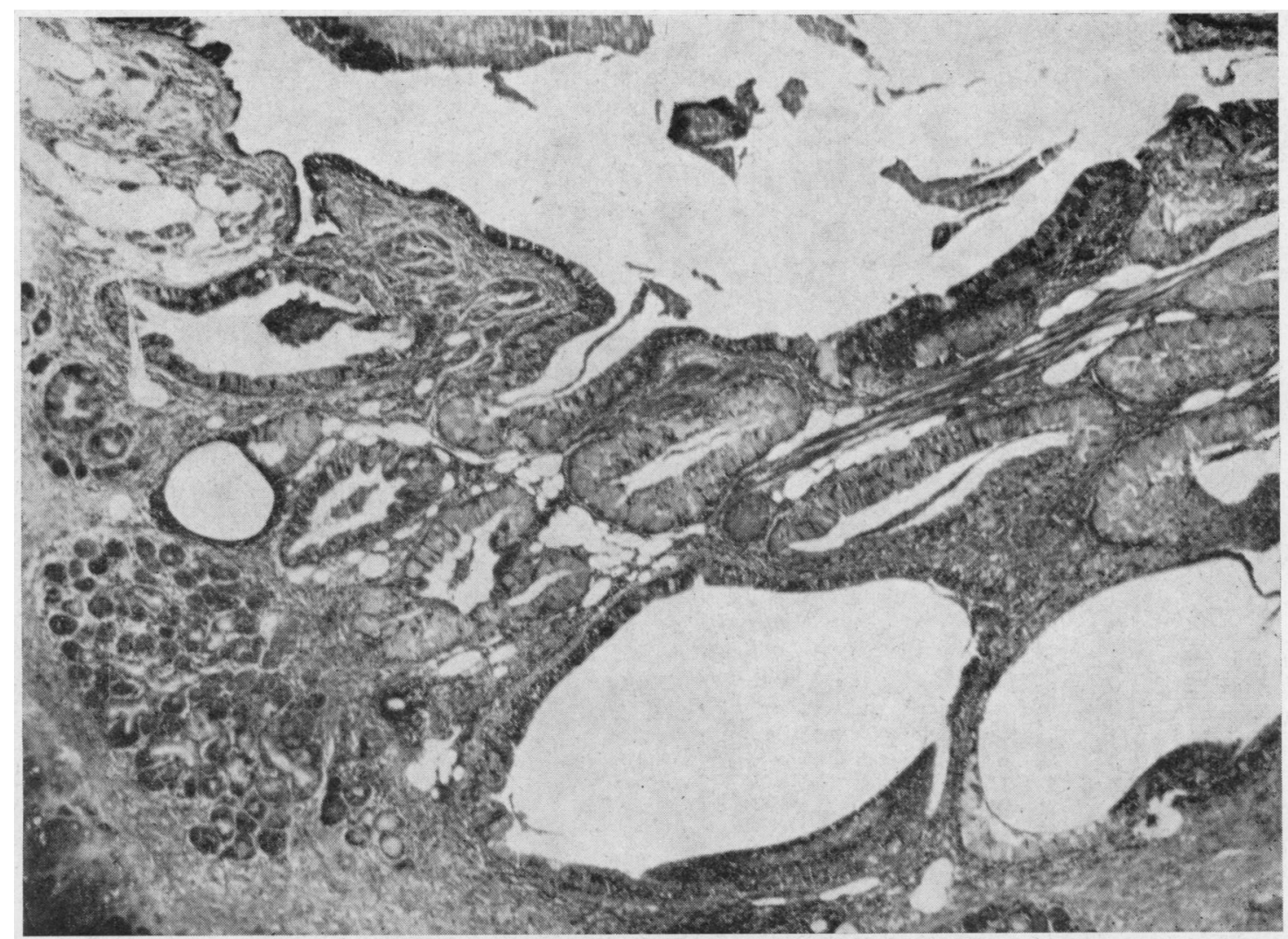

FIG. 12. Case 3. Extreme goblet-cell hyperplasia of mucous glands, some of which show cyst-formation outside the ring of bronchial muscle. Haematoxylin-eosin. $\quad \times 40$.

TREATMENT A follow-up of the first 36 cases by the Texas University group indicated that surgery was more effective than medical treatment, as regards both general health and asthmatic status (Shaw et al., 1957). But since the introduction of acetylcysteine, a powerful mucolytic agent, they now regard mucoid impaction as predominantly medically remediable. The acetylcysteine can be administered by either aerosol or intratracheal injection, and may be combined with insufflated detergents and bronchodilators, as well as systemic antibiotics. Postural drainage and physiotherapy are also recommended. Surgery is reserved for cases where the diagnosis is in doubt, or for lung abscess or bronchiectasis with extensive destruction of lung tissue (Urschel et al., 1966).

PATHOGENESIS Hutcheson et al. (1960) reviewed the pathology of 27 specimens of lung removed surgically by the Texas University team, and suggested the following as factors predisposing to impaction :
(1) narrowing of the bronchus due to asthmatic spasm or post-inflammatory fibrosis ;

(2) hypersecretion of viscid (asthmatic) mucus ;

(3) dehydration of secretions, most cases having been reported from areas where there is a constant low humidity factor;

(4) secondary bacterial invasion of the bronchial wall, causing ulceration and organization of the plug from the periphery.

The frequency of upper lobe involvement was attributed by Shaw et al. (1957) to its being less subject than the other lobes to the force of coughing. The fact that allergic pneumonia in chronic asthmatics often has the same distribution (Leopold, 1961) does not necessarily invalidate this argument.

\section{ASTHMA AND MUCOID IMPACTION}

When Huber and Koessler wrote their classical account of the morbid anatomy of asthma in 1922 , they were able to find only 15 necropsy 


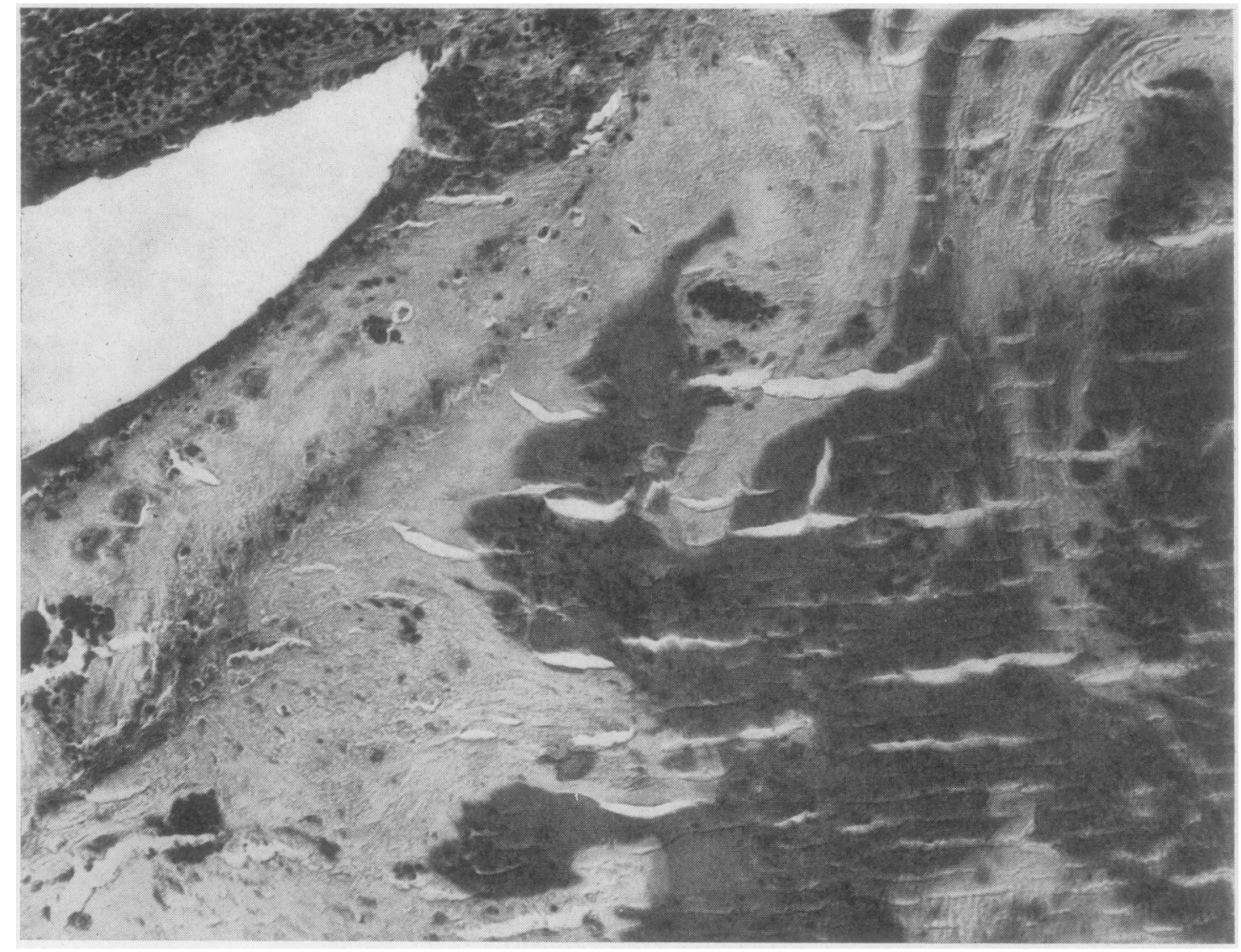

FIG. 13. Case 3. Lakes of acidophilic (darker staining) material which stain like fibrin. M.S.B. $\quad \times 120$.

studies between 1886 and 1921 in which there had been any attempt at the detailed microscopy. Two of these referred to obstruction of a major bronchus by viscid mucocellular casts (Berkart, 1889 ; Jezierski, 1905). From the elaborate study of their own cases Huber and Koessler (1922) found that the most consistent changes in asthmatic lungs were thickening of the bronchial wall and tissue eosinophilia (the thickening being due to a combination of hypertrophy of mucous glands and smooth muscle), and the less specific features of chronic bronchitis - thickening of the basement membrane and round-celled infiltration of the submucosa. They noted the cellular nature of the mucous plugs and the distension of mucous gland ducts (compare our Fig. 11). An interesting observation was that these changes may vary in degree, even within the same pulmonary lobe (compare our case 3). Recent biopsy studies have shown hyperplasia of the surface goblet cells in the bronchial mucosa and patchy squamous metaplasia (Glynn and Michaels, 1960).

Houston, de Navasquez, and Trounce (1953), in a review of nine fatal cases of status asthmaticus, stressed the widespread detachment of superficial ciliated epithelium from most parts of the bronchial tree, which they regarded as responsible for the mucocellular secretion causing bronchial obstruction in status asthmaticus. Naylor (1962) attributed the shedding of ciliated epithelium to intercellular oedema from the inflamed submucosa, and observed cystic distension of mucous glands in fatal cases of status asthmaticus. Four of his 20 cases also showed cystic bronchiectasis.

It is thus clear that many of the pathological changes described in mucoid impaction (including localized bronchiectasis and impacted casts in medium-sized bronchi) have also been observed at necropsies on asthmatic subjects.

\section{PLASTIC BRONCHITIS AND MUCOID IMPACTION}

Several writers have suggested that mucoid im- 
paction is related to plastic (or fibrinous) bronchitis. This condition, although rarely mentioned in modern textbooks of pathology, attracted considerable attention in the nineteenth century. The diagnosis was based exclusively on the expectoration of tough bronchial casts, sometimes accompanied by haemoptysis, and occasionally preceded by bouts of fever and dyspnoea, which were relieved by coughing up the casts. Numerous case reports can be found in the Transactions of the Pathological Society of London between 1853 and 1889.

Pathological studies were confined to microscopy and crude chemistry of the casts, and opinion was divided on whether they were mucinous, fibrinous or both (Leggat, 1954). The presence of eosinophils and Charcot-Leyden crystals in some casts suggested an asthmatic origin, but in others these features were definitely lacking (Bettmann, 1902).

Clinically, asthma is recorded in only a minority of cases, but more recently accounts of plastic bronchitis suggest that some individuals may be allergic even though not clinically asthmatic. This aspect will be referred to later.

According to Johnson and Sita-Lumsden (1960), $15 \%$ of cases of plastic bronchitis react positively to aspergillus antigen, although not necessarily suffering from bronchopulmonary aspergillosis. They quote the case of a woman with a 20-year history of asthma-like attacks, complicated in later years by pyrexial bouts during which bronchial casts were expectorated. These contained eosinophils, Curschmann's spirals, and Charcot-Leyden crystals, and a bronchial biopsy showed tissue eosinophilia. Her skin tests were strongly positive to the antigens of aspergillus and mixed fungi. This case strikingly illustrates the overlap between mucoid impaction, plastic bronchitis, asthma, and aspergillosis.

Sanerkin et al. (1966) re-examined casts from published cases of plastic bronchitis and found them indistinguishable from those seen in mucoid impaction, status asthmaticus, and some cases of bronchopulmonary aspergillosis. They postulated that all resulted from the combined effects of allergic and catarrhal inflammation. This, however, must be an oversimplification in view of the earlier literature in which clinical asthma and allergic stigmata in the bronchial casts were often specifically excluded.

We have analysed 11 cases of plastic bronchitis published between 1923 and 1950 (Ash and Brodribb, 1924 ; Izzo and Casanegra, 1933 ; Johnstone, 1945 ; Malamud and Lisman, 1946 ; Merica, 1950 ; Mulligan and Spencer, 1924 ; Nunzi, 1934 ;
Perlstein, 1930 ; Rakower, 1938 ; Rodenbaugh, 1923) in patients none of whom was described as asthmatic or had a blood eosinophilia, although eosinophils were present in the bronchial casts of three patients. In the sole necropsy study it was noted that the bronchial mucosa was intact, but the mucous glands were hyperplastic (Izzo and Casanegra, 1933).

We conclude that plastic bronchitis is a clinical rather than a pathological entity, and that allergy is only one of its causes. Some of the earlier case reports in which asthma was a factor would probably be regarded as mucoid impaction today, for example the case of Luke (1956).

\section{BRONCHIAL CASTS AND ALLERGY}

Plastic bronchitis was formerly known as fibrinous bronchitis, but this term is now discredited, since the more elaborate studies in the literature suggest that the amount of fibrin in bronchial casts is quite small. The identification of fibrin is notoriously difficult, partly because it becomes rapidly denatured (Lendrum, Fraser, Slidders, and Henderson, 1962), and this is reflected not only in staining techniques but in its identification by fibrinolysins or immunofluorescent staining.

A dual staining reaction in the casts has been noted by many authors. We believe that many of the ragged clumps which stain deep purple with P.T.A.H. are not fibrin but condensed nuclear debris (Fig. 9) ; but the more sharply outlined lakes which also stain red with Martius Scarlet and Blue (considered by Lendrum et al. (1962) to be one of the more reliable methods for fibrin) are clearly a homogeneous fluid, the nature of which is not readily explained (Fig. 13).

We stress this point because the viscosity of the casts in plastic bronchitis was for many years attributed to a high fibrin content, but if this is really negligible, other explanations must be sought. We have already referred to the dehydration factor in relation to mucoid impaction, which is said to occur more frequently in regions where the atmospheric humidity is low; and we have recently encountered a hard cast obstructing the right main bronchus of a patient who had a permanent tracheostomy and died suddenly. The subject was not asthmatic, and neither cast nor lungs showed allergic features. We are therefore prepared to accept the fact that bronchial casts following tracheostomy may result from loss of tussive efficiency and dehydration (Spencer, 1962).

The viscosity of bronchial secretions in ordinary asthmatic attacks cannot be explained in this way ; and plastic bronchitis has been recorded in several 
European countries where the humidity factor is relatively high. There must therefore be some other explanation.

Brogan (1959) showed that the sputum of chronic bronchitis contains mucopolysaccharides and mucoproteins, some of the latter being derived from the nuclei of degenerating leucocytes. Bürgi (1964) demonstrated D.N.A. fibres in the sputum of asthmatics, to which he attributed the increased viscosity. This is an attractive suggestion, and it is tempting to think that the common factor in the bronchial secretions of asthma, plastic bronchitis, and mucoid impaction would be the high cell content, whether from pus cells, eosinophils or desquamated epithelium, cell breakdown leading to production of D.N.A. which increases the viscosity of the mucus. On this theory there would be no need to postulate an allergic basis for all bronchial casts.

In the case of mucoid impaction (as distinct from plastic bronchitis generally) the allergic factor cannot be ignored, having been noted in 96 out of 128 cases. In the series we have analysed, 25 out of 34 patients were frankly asthmatic, and 6 of the remaining 9 showed eosinophilia of the blood, sputum, or tissues. It is worth noting that impaction of viscid casts in allergic subjects is not confined to the bronchial tree, and has twice been observed by us in the ethmoidal labyrinth in cases of allergic rhinitis with multiple polyps. In one case there was a blood eosinophilia of 2,120 per $\mathrm{cu}$. mm. and in both the casts contained eosinophils and Charcot-Leyden crystals.

Nasal allergy has occasionally been reported in cases of mucoid impaction of the bronchi (Greer, 1957, and our case 2) and also in some cases of plastic bronchitis (Walker, 1920 ; Sanerkin et al., 1966).

In a complex review which involves several syndromes and the distillation of a much larger medical literature than can be conveniently referred to here, it may be helpful to summarize our conclusions as follows.

An analysis of published cases indicates that the pathologies of asthma, mucoid impaction, and plastic bronchitis are not identical although they overlap considerably.

Mucoid impaction is not a new disease and is probably more common in this country than the literature suggests, earlier cases having been diagnosed or published as examples of plastic bronchitis or atypical asthma.

Plastic bronchitis is a clinical entity characterized by the expectoration of casts, but its pathology is varied, and only a minority of the case records involve asthmatics. Mucoid impac- $\stackrel{\overrightarrow{\bar{s}}}{\stackrel{5}{5}}$ tion, on the other hand, is characterized by the retention of casts, not simply by their expectora- $\frac{\bar{\sigma}}{\bar{\alpha}}$ tion, and a very high proportion of cases are $\overrightarrow{\widetilde{d}}$ asthmatic or have other stigmata of allergy.

The changes in the lungs in mucoid impactionis are generally those of asthma complicated by re- $\overrightarrow{0}$ tention of a localized mucocellular cast in $a-$ bronchus generally larger than those obstructed in $\vec{\omega}$ plastic bronchitis or status asthmaticus. The visco-? sity of the casts in all three conditions is more $\vec{x}$ likely to be due to the nature of the secretion than N to purely climatic conditions, and a possible factor + is its high nuclear content.

The relative rarity of mucoid impaction in asthmatics suggests that a secondary factor may be involved, the nature of which is unknown.

We are indebted to the following colleagues for clinical data: Mr. Charles Drew, Mr. Miles Foxen, $\vec{\varnothing}$ and Mr. C. A. Holborow; to Dr. Basil Strickland for $\infty$ assistance with the radiographs; to Mr. J. F. Wilson and Mrs. C. Dowsett for technical assistance; and to the Department of Medical Photography for the illustrations.

\section{REFERENCES}

Ash, B., and Brodribb, C. (1924). Fibrinous bronchitis resembling tuberculosis of the lung. Brit. med. J., 1, 192.

Berkart, J. B. (1889). On Bronchial Asthma. 2nd ed., p. 75. Churchill, London.

Bettmann, M. (1902). Report of a case of fibrinous bronchitis, with a review of all cases in the literature. Amer. J. med. Sci., 123, 304.

Brogan, T. D. (1959). The carbohydrate complexes of bronchial secretion. Biochem. J., 71, 125.

Bürgi, H. (1964). Mucoproteins and sputum viscosity. Lancet, 2, 644.

Carlson, V., Martin, J. E., Keegan, J. M., and Dailey, J. E. (1966). 3 Roentgenographic features of mucoid impaction of the bronchi. Amer. J. Roentgenol., 96, 947.

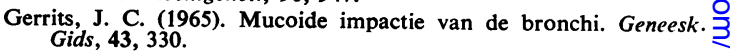

Glynn, A. A., and Michaels, L. (1960). Bronchial biopsy in chronic $\bigcirc$ bronchitis and asthma. Thorax, 15, 142 . Greer, A. E. (1957). Mucoid impaction of the bronchi. Ann. intern $\frac{D}{O}$
Med., 46, 506.

Harvey, C., Blacket, R. B., and Read, J. (1957). Mucoid impaction of the bronchi. Aust. Ann. Med., 6, 16 .

Hekking, A. M. W., and Goemans, T. (1957). Een afsluitende slijm-S prop ("mucoid impaction") van de bronchi. Ned. T. Geneesk., N

Hinson, K. F. W., Moon, A. J., and Plummer, N. S. (1952). Broncho- $\omega$ pulmonary aspergillosis. Thorax, $7,317$.

Houston, J. C., de Navasquez, S., and Trounce, J. R. (1953) A clinical and pathological study of fatal cases of status asthmaticus. Ibid., 8, 207. Huber, H. L., and Koessler, K. K. (1922). The pathology of bronchial $\mathbb{D}$
asthma. Arch. intern. Med., 30, 689.

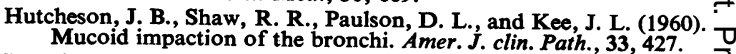

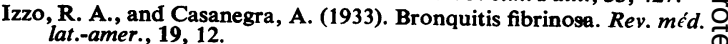

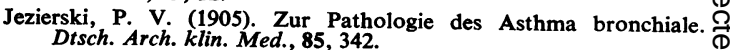
Johnson, R. Sleigh, and Sita-Lumsden, E. G. (1960). Plastic bronchitis. $\frac{Q}{\sigma}$
Thorax, 15, 325.

Johnstone, D. F. (1945). Acute plastic bronchitis, with case report. Guy's Hosp. Gaz., 59, 2.

Keeley, R. L. A., and Snead, J. G. (1965). Mucoid impaction of the bronchus. Va med. Mon., 92, 367

Leggat, P. O. (1954). Plastic bronchitis. Dis. Chest, 26, 464. 
Lendrum, A. C., Fraser, D. S., Slidders, W., and Henderson, R. (1962). Studies on the character and staining of fibrin. J. clin. Path., 15, 401.

Leopold, J. G. (1961). Allergic pneumonia in chronic asthmatics. Thorax, 16, 400 .

Luke, C. M. (1956). Massive collapse of the lung in bronchitis and bronchial asthma. Brit. J. Tuberc., 50, 285.

Malamud, T., and Lisman, A. (1946). Atelectasia aguda de un lóbulo pulmonar en una bronquitis pseudo membranosa frusta. Pren. méd. argent., 33, 2362.

Mannes, P., and Severin, A. (1958). Manifestations récidivantes d'obstruction bronchique par de volumineux bouchons de mucus. $J$. franc. Méd. Chir. thorac., 12, 164.

Merica, F. W. (1950). Acute fibrinous bronchitis with massive atelectasis. Ohio St. med. J., 46, 1079.

Mulligan, P. B., and Spencer, R. D. (1924). Chronic fibrinous bronchitis as a symptom of mediastinal compression. J. Amer. med. Ass., 82, 791 .

Naylor, B. (1962). The shedding of the mucosa of the bronchial tree in asthma. Thorax, 17, 69.

Nunzi, A. (1934). Intervento per via bronchoscopica in caso di bronchite fibrinosa e sindrome soffocante. Valsalva, 10, 253.

Perlstein, R. N. (1930). A case of fibrinous bronchitis complicated by massive atelectasis. Amer. Rev. Tuberc., 22, 82.

Rakower, J. (1938). Atelectasie massive au cours de la bronchite pseudo-membraneuse primitive. Presse méd., 46, 1116.

Rodenbaugh, F. H. (1923). Fibrinous bronchitis. Amer. J. Roentgenol., 10,843 .
Sanerkin, N. G., Seal, R. M. E., and Leopold, J. G. (1966). Plastic bronchitis, mucoid impaction of the bronchi and allergic bronchopulmonary aspergillosis, and their relationship to bronchial asthma. Ann. Allergy, 24, 586.

Shaw, R. R. (1951). Mucoid impaction of the bronchi. J. thorac. Surg., 22, 149.

- Paulson, D. L., and Kee, J. L. (1957). Mucoid impaction of the bronchi. Amer. Rev. Tuberc., 76, 970.

Sheehan, V. A., and Schonfeld, M. D. (1963). Mucoid impaction simulating tumor. Radiology, 80, 811 .

Smith, W. G., and Clark, F. J. (1964). Mucoid impaction of the bronchi. Aust. Ann. Med., 13, 40.

Spencer, H. (1962). Pathology of the Lung, p. 391. Pergamon Press, Oxford.

Tsai, S. H., and Jenne, J. W. (1966). Mucoid impaction of the bronchi Amer. J. Roentgenol., 96, 953.

Urschel, H. C., Paulson, D. L., and Shaw, R. R. (1966). Mucoid impaction of the bronchi. Ann. thorac. Surg., 2, 1.

Walker, I. C. (1920). Two cases of fibrinous bronchitis, with a review of the literature. Amer. J. med. Sci., 159, 825.

Waring, W. W., Brunt, C. H., and Hilman, B. C. (1967). Mucoid impaction of the bronchi in cystic fibrosis. Pediatrics, 39, 166.

Welsh, R. A. (1959). The genesis of the Charcot-Leyden crystal in the eosinophilic leukocyte of man. Amer. J. Path., 35, 1091.

Wilson, W. (1964). Mucoid impaction of the bronchi. Brit. J. Radiol., $37,590$. 